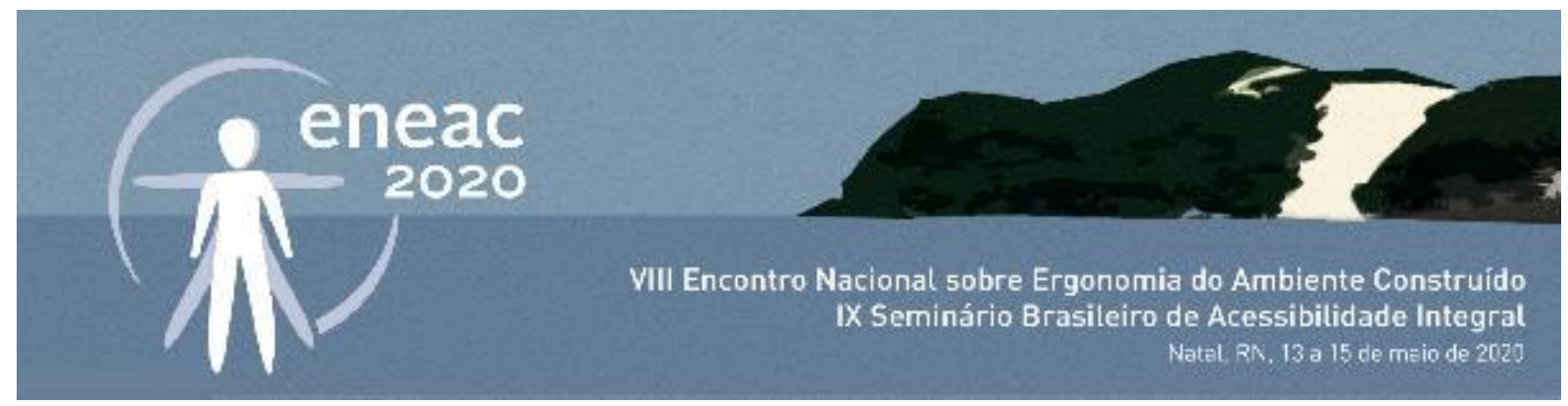

\title{
Políticas públicas de inclusão no contexto universitário
}

\author{
Public policies of inclusion in the university
}

FRANCISCO RICARDO LINS VIEIRA DE MELO

Dr. em Educação; docente UFRN, presidente da SIA/UFRN; ricardolins67@gmail.com

\section{RESUMO}

A proposta desta fala é dialogar com a colega que compõe a mesa, contribuindo com reflexões em torno das políticas públicas no campo da inclusão a partir de um recorte específico, o meio universitário. A base para desenvolvimento destes comentários é o olhar proporcionado pela minha atuação como gestor responsável pela Política de inclusão e Acessibilidade da Universidade Federal do Rio Grande do Norte (UFRN), que me permite contextualizar o processo histórico de incorporação e implementação desta política na instituição e seus desdobramentos ao longo dos últimos dez anos (2010-2019). Essa trajetória será delineada de forma crítica, destacando pontos que foram fundamentais para repensar o papel da Comissão Permanente de Apoio ao Estudante com Necessidade Educacional Especial - CAENE (criada em 2010) - até sua transformação e institucionalização como Secretaria de Inclusão e Acessibilidade - SIA (2019). Para tanto, ressalto a importância/significado de dois marcos: (i) o Programa Incluir, criado em 2005, pela SECADI/MEC, para o avanço das políticas e ações de inclusão voltadas para o acesso e a permanência para às pessoas com deficiência na Educação Superior; (ii) a Lei no. 13.409/2016, que prevê a reserva de vagas para pessoas com deficiência nos cursos técnico de nível médio e superior das instituições federais de ensino. Será especialmente destacado o impacto desta última, proporcionando a mudança de direcionamento para uma nova perspectiva de trabalho junto às pessoas com deficiência e outras necessidades específicas na UFRN, fundamentada nas Comissões Permanentes de Inclusão e Acessibilidade (CPIA). Finalizo reforçando minhas expectativas futuras quanto ao fortalecimento da política de Inclusão e Acessibilidade e a construção de uma cultura universitária inclusiva.

PALAVRAS-CHAVE: Inclusão, Políticas Públicas, Gestão Universitária, UFRN. 